\title{
Crystal Structure of 2-Se-(2-methyl-2-propenyl)-1-benzoic Acid
}

\author{
Federico Martínez Ramos* and Manuel Soriano-García**广
}

*Departamento de Química Inorgánica, Escuela Nacional de Ciencias Biológicas, I. P. N. Prolongación Carpió y Plan de Ayala 11340, México D. F., México

**Departamento de Bioestructura, Instituto de Química, UNAM, Circuito Exterior,

C. U., Coyoacán, México D. F. 04510, México

\begin{abstract}
$\mathrm{C}_{11} \mathrm{H}_{12} \mathrm{O}_{2} \mathrm{Se}$ is triclinic, $P \overline{1}$. Unit-cell dimensions at $293 \mathrm{~K}$ are $a=5.8450(10), b=8.1490(10), c=11.4620(10) \AA, \alpha=$ 97.050(10), $\beta=90.140(10), \gamma=90.120(10)^{\circ}, V=541.81(12) \AA^{3}, D_{\mathrm{x}}=1.564 \mathrm{~g} / \mathrm{cm}^{3}$, and $Z=2$. The $R$ value is 0.047 for 1388 observed reflections. The dihedral angle between the phenyl ring and the isobutenyl group is $72.3(2)^{\circ}$. There is an intermolecular hydrogen bond between two symmetry-related carbonyl groups with an $\mathrm{O} 1 \cdots \mathrm{O} 2$ distance of 2.669(6)A. The molecules in the crystal are packed at normal van der Waals distances.
\end{abstract}

(Received September 9, 2002; Accepted February 3, 2003)

Selenium is well recognized as an important "dietary" antioxidant. ${ }^{1}$ It is recognized as being an essential component of the active sites of a number of enzymes, including the glutathione peroxidase selenoenzyme family, which scavenges hydroperoxides to prevent cellular damage. ${ }^{2}$ Dietary selenium deficiency has been linked to diseases as diverse as cancer, heart disease, arthritis and AIDS. ${ }^{2}$ Thus, the pharmacology, biology and biochemistry of selenium metabolism have become of considerable interest, which are spurring efforts to develop synthetic selenium-containing compounds as possible therapeutic agents. ${ }^{2}$ We are currently working on the synthesis of a new series of agents containing selenium, such as 2-Se-(2methyl-2-propenyl)-1-benzoic acid (Fig. 1). In this paper, we present the crystal structure of (1).

The title compound was prepared by a method described in the literature. ${ }^{3}$ A detailed description of the experimental

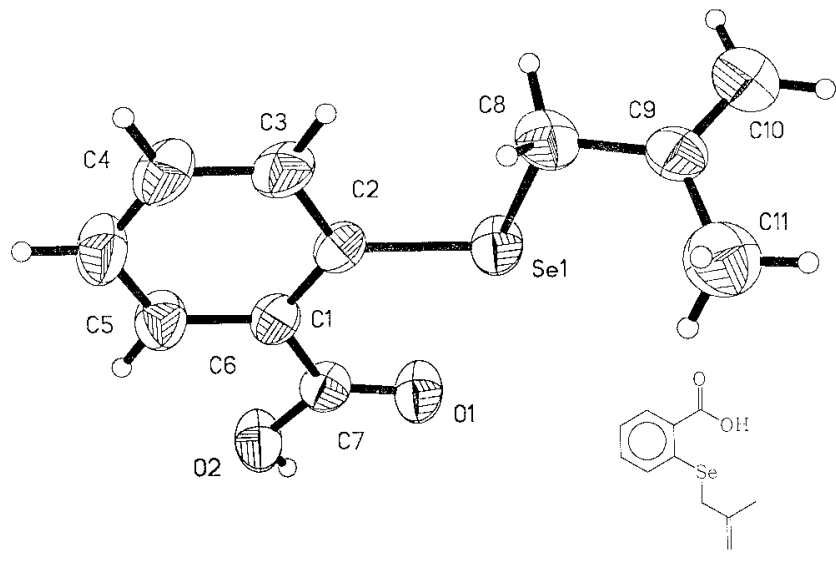

(1)

Fig. 1 Molecular structure of the title compound with atom labeling. Thermal ellipsoids are drawn at the $50 \%$ probability level.

$\doteqdot$ To whom correspondence should be addressed. synthesis will be reported elsewhere. The obtained material was recrystallized from chloroform:isopropyl ether $(1: 1)$ to give a colorless crystal (m.p. $\left.133-135^{\circ} \mathrm{C}\right)$; IR $\left(1672 \mathrm{~cm}^{-1}, \mathrm{CO}\right)$; NMR (1.93 ppm, $\mathrm{C} 11-\mathrm{CH}_{3} ; 3.6$ ppm, 8- $\mathrm{CH}_{2} ; 5$ ppm, $10-\mathrm{CH}_{2} ; 7.2-8.2$

Table 1 Crystal and experimental data

Formula: $\mathrm{C}_{11} \mathrm{H}_{12} \mathrm{O}_{2} \mathrm{Se}$

Formula weight $=255.17$

Crystal system: triclinic

Space group: $P \overline{1} \quad Z=2$

$a=5.8450(10) \AA$

$b=8.1490(10) \AA$

$c=11.4620(10) \AA$

$\alpha=97.050(10)^{\circ}$

$\beta=90.140(10)^{\circ}$

$\gamma=90.120(10)^{\circ}$

$V=541.81(12) \AA^{3}$

$D_{\mathrm{x}}=1.564 \mathrm{~g} / \mathrm{cm}^{3}$

$D_{\mathrm{m}}=1.566 \mathrm{~g} / \mathrm{cm}^{3}$ (measured by flotation)

$\mu\left(\mathrm{Mo} \mathrm{K}_{\alpha}\right)=3.436 \mathrm{~mm}^{-1}$

$T=293 \mathrm{~K}$

Colorless

$F\left(\begin{array}{lll}0 & 0 & 0)\end{array}\right) 256$

$0.32 \times 0.20 \times 0.16 \mathrm{~mm}$

Radiation: Mo $\mathrm{K}_{\alpha}$

$2 \theta / \theta$ scans with $2 \theta_{\max }=50^{\circ}$

$R=0.0468\left(\right.$ on $\left.F^{2}\right)$

$R w=0.088\left(\right.$ on $\left.F^{2}\right)$

$(\Delta / \sigma)_{\max }=0.086$

$(\Delta \rho)_{\max }=0.318 \mathrm{e}^{-3}$

$(\Delta \rho)_{\min }=-0.348 \mathrm{e}^{-3}$

No. of reflections measured $=1893$

No. of reflections used $=1388$

No. of parameters $=131$

Goodness-of-fit $=1.026$

Measurement: Siemens P4/PC diffractometer

Program system: SHELXL-Plus

Structure determination: direct methods (SHELXS-97)

Refinement: full matrix least-squares (SHELXL-97) 
Table 2 Final atomic coordinates and equivalent isotropic temperature factors $\left(\AA^{2}\right)$

\begin{tabular}{ccccl}
\hline Atom & $x$ & $y$ & $z$ & \multicolumn{1}{c}{$U_{\text {eq }}$} \\
\hline Se1 & $0.39723(13)$ & $0.51390(8)$ & $0.73186(6)$ & $0.0474(2)$ \\
O1 & $0.7754(8)$ & $0.4992(5)$ & $0.5884(4)$ & $0.0539(11)$ \\
O2 & $0.9727(8)$ & $0.2804(5)$ & $0.5088(4)$ & $0.0581(13)$ \\
C1 & $0.6630(10)$ & $0.231(6)$ & $0.6293(5)$ & $0.0396(13)$ \\
C2 & $0.4716(10)$ & $0.2846(6)$ & $0.6980(5)$ & $0.0405(13)$ \\
C3 & $0.3341(11)$ & $0.1638(7)$ & $0.7397(6)$ & $0.0521(16)$ \\
C4 & $0.3902(13)$ & $-0.0004(8)$ & $0.7191(6)$ & $0.0574(17)$ \\
C5 & $0.5801(13)$ & $-0.0537(7)$ & $0.6551(6)$ & $0.0605(18)$ \\
C6 & $0.7146(11)$ & $0.0627(7)$ & $0.6103(6)$ & $0.0523(16)$ \\
C7 & $0.8046(10)$ & $0.3497(7)$ & $0.5747(5)$ & $0.0416(13)$ \\
C8 & $0.1552(11)$ & $0.5040(7)$ & $0.8505(5)$ & $0.0521(16)$ \\
C9 & $0.1231(10)$ & $0.6747(8)$ & $0.9114(6)$ & $0.0496(15)$ \\
C10 & $-0.0523(13)$ & $0.7642(10)$ & $0.8879(7)$ & $0.074(2)$ \\
C1 1 & $0.2978(14)$ & $0.7361(10)$ & $1.0012(7)$ & $0.079(2)$ \\
\hline
\end{tabular}

$U_{\text {eq }}=(1 / 3) \Sigma_{i} \Sigma_{j} U_{i j}\left(a_{i} * a_{j}^{*}\right)\left(\boldsymbol{a}_{i} \cdot \boldsymbol{a}_{j}\right)$.

ppm, H-aromatic; 11 ppm, -COOH).

The X-ray data for crystals of the title compound were collected by graphite-monochromatized $\mathrm{Mo} \mathrm{K}_{\alpha}$ radiation at 293 K. An analytical face-indexed absorption correction was applied. The structure was solved by direct methods and refined by full-matrix least-squares with anisotropic temperature factors for the non-hydrogen atoms. The hydrogen atoms bonded to the carbon atoms were assigned based on the expected bonding geometry. The hydrogen atom bonded to the hydroxyl group was found in a difference map and its coordinates refined in the final least-squares cycles. The final atomic parameters for hydrogen atoms, and observed and calculated structure factors may be obtained from the second author. The software used to prepare material for publication was PARST97.4 Table 1 summarizes the crystal and experimental data. The molecular structure is shown in Fig. 1.

The phenyl ring and the isobutenyl group at Sel are planar within the experimental error, and the dihedral angle between them is $72.3(2)^{\circ}$. This conformation keeps the Se atom's unshared electron pairs in a more stable configuration with the rest of the molecules. The dihedral angle between the planes of
Table 3 Selected bond distances $(\AA)$ and angles $\left({ }^{\circ}\right)$

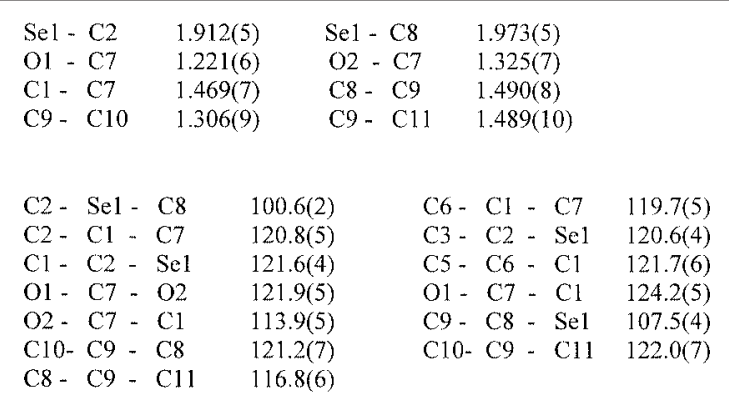

the carboxyl group at $\mathrm{C} 1$ and the isobutenyl moiety is $75.8(3)^{\circ}$. There is an intermolecular hydrogen bond between two symmetry-related carbonyl groups $(-x+2,-y+1,-z+1)$ with an $\mathrm{O} 1 \cdots \mathrm{O} 2$ distance of $2.669(6) \AA$. There is one intermolecular contact between $\mathrm{C} 6 \cdots \mathrm{O} 2,3.481(7) \AA(-x+2,-y,-z+1)$. Apart from the intermolecular hydrogen bond, a $\mathrm{C} \cdots \mathrm{O}$ contact, the packing in the crystal is entirely due to van der Waals forces. The final atomic coordinates and equivalent isotropic temperature factors are given in Table 2. Selected bond distances and angles are listed in Table 3.

\section{Acknowledgements}

Contribution No. 1767 of the Instituto de Química, UNAM.

\section{References}

1. G. F. Combs, Jr., Medizinische Klinik., 1999, 94, 18.

2. S. W. May and S. H. Pollock, Drugs, 1998, 56, 959.

3. A. Ruwet and M. Renson, Bull. Soc. Chim. Belges, 1966, $75,157$.

4. M. Nardelli, J. Appl. Cryst., 1995, 28, 659. 